\title{
FUNCTIONAL ELBOW AND WRIST REHABILITATION PROTOTYPE CONTROLLED BY COMPUTER
}

\author{
PROTOTIPO DE REHABILITACIÓN FUNCIONAL DE CODO \\ Y MUÑECA CONTROLADO MEDIANTE COMPUTADOR
}

Milton Gonzalo Acosta Jarrín ${ }^{1}$, Flavio Minos Pineda López ${ }^{1}$, Patricia Gabriela Moya Cáceres ${ }^{1}$, Stephanie Carolina Vásquez Gabela ${ }^{1}$ ${ }^{1 .}$ Universidad de las Fuerzas Armadas-ESPE; Sangolquí, Ecuador.

Recibido: 10 Febrero de 2015

Aceptado: 15 Febrero de 2016

* Correspondencia del autor: Milton Gonzalo Acosta Jarrín. E-mail: mgacosta@espe.edu.ec

\begin{abstract}
On this project, we have considered the anthropometrics of the human arm, taking in consideration the movements and angles of the elbow and wrist by developing a prototype for the first and second phases of rehabilitation as the main goal the patient could achieve full joints mobility. The implementation of this prototype consists in four different adaptations, one for each movement, an interface electronic board of sensors, a control board, and a graphical interface of the user where the physiotherapist is able to set up a personalized rehabilitation cycle responding to the patient needs.

We have done field tests of the prototype with a patient with elbow and wrist fracture diagnosis. The results of these tests showed an improvement in the mobility of both joints through a small number of rehabilitation sessions. Thus, it is concluded that the prototype allows the patient the progressive reach of angles nearer to the angular limits of pronation-supination of the elbow and flexion-extension of the wrist, with a reduction of $50 \%$ of number of session using conventional methods.
\end{abstract}

Keywords: rehabilitation; wrist; elbow; servomotor; Arduino 


\begin{abstract}
RESUMEN
En este proyecto, hemos considerado la antropometría del brazo humano, teniendo en cuenta los movimientos y los ángulos del codo y la muñeca mediante el desarrollo de un prototipo para la primera y segunda fase de rehabilitación; como meta principal, el paciente podría lograr movilidad completa de las articulaciones. La implementación de este prototipo consiste de cuatro diferentes adaptaciones, una para cada movimiento, una interface de la tarjeta electrónica de sensores, un tablero de control y una interface gráfica del usuario donde el fisioterapeuta puede establecer un ciclo personalizado de rehabilitación en respuesta a las necesidades del paciente. Se realizaron pruebas de campo del prototipo con un paciente con diagnóstico de fractura de codo y muñeca. Los resultados de estas pruebas demostraron mejoría en la movilidad de ambas articulaciones mediante un pequeño número de sesiones de rehabilitación. Así, se concluye que el prototipo le permite al paciente el alcance progresivo de los ángulos más cercanos a los límites angulares de la pronación-supinación del codo y la flexión-extensión de la muñeca, con reducción de 50\% del número de sesiones que utilizan métodos convencionales.
\end{abstract}

Palabras claves: rehabilitación; muñeca; codo; servomotor; Arduino

\section{INTRODUCTION}

The goal of rehabilitation is to achieve the maximum potential for function and normal activities. It consists of a procedure in which the patient improves the mobility progressively and increases the strength of the joint or muscle affected. Therapeutic robotics seems to accelerate the rehabilitation process due to its accuracy. Thus, we have considered the design of a prototype controlled by the computer for the rehabilitation of the wrist and elbow of an adult. The patient will exercise in a passive way to achieve the full range of motion of the joints of the elbow and wrist during the first and second phases of rehabilitation.

In order to maintain the safety of the patient, the physiotherapist is able to set up the information regarding the area to treat (elbow or wrist), movement to do (flexion-extension, pronation-supination of the elbow, flexion-extension, abduction-adduction of the wrist), the angle of each movement $\left(0^{\circ}-130^{\circ},-90^{\circ}-+90^{\circ}\right.$, $-70^{\circ}-+70^{\circ},-30^{\circ}-+15^{\circ}$, respectively) and the speed (low-speed, normal-speed, high-speed) according to the patient's progress. The process controls the angle, sense of rotation and position through the communication between Matlab and Arduino.

\section{DESIGN AND IMPLEMENTATION OF THE ELBOW AND WRIST REHBAILITATION PRO- TOTYPE}

The movements, angles and dimensions of the upper extremity involved in the rehabilitation prototype are shown in the Table 1.

The architecture of the rehabilitation system is based on the diagram shown in the Figure. 1. The interface of the user allows data input which is transmitted to the Arduino controller. The controller sends the corresponding signal to the actuator and the mechanisms. During the whole process the sensors are controlling the variables in order to execute the rehabilitation properly.

The prototype is meant to be used by an adult who needs to rehabilitate either the left or right upper extremity. The design contemplates as the minimum dimensions of women and maximum dimensions of men in order to make this prototype adaptable to any kind of patient. The dimensions were shown previously in Table 1 in the corresponding column. 
TABLE 1. ANTHROPOMORPHIC CONSIDERATIOS FOR THE DESIGN

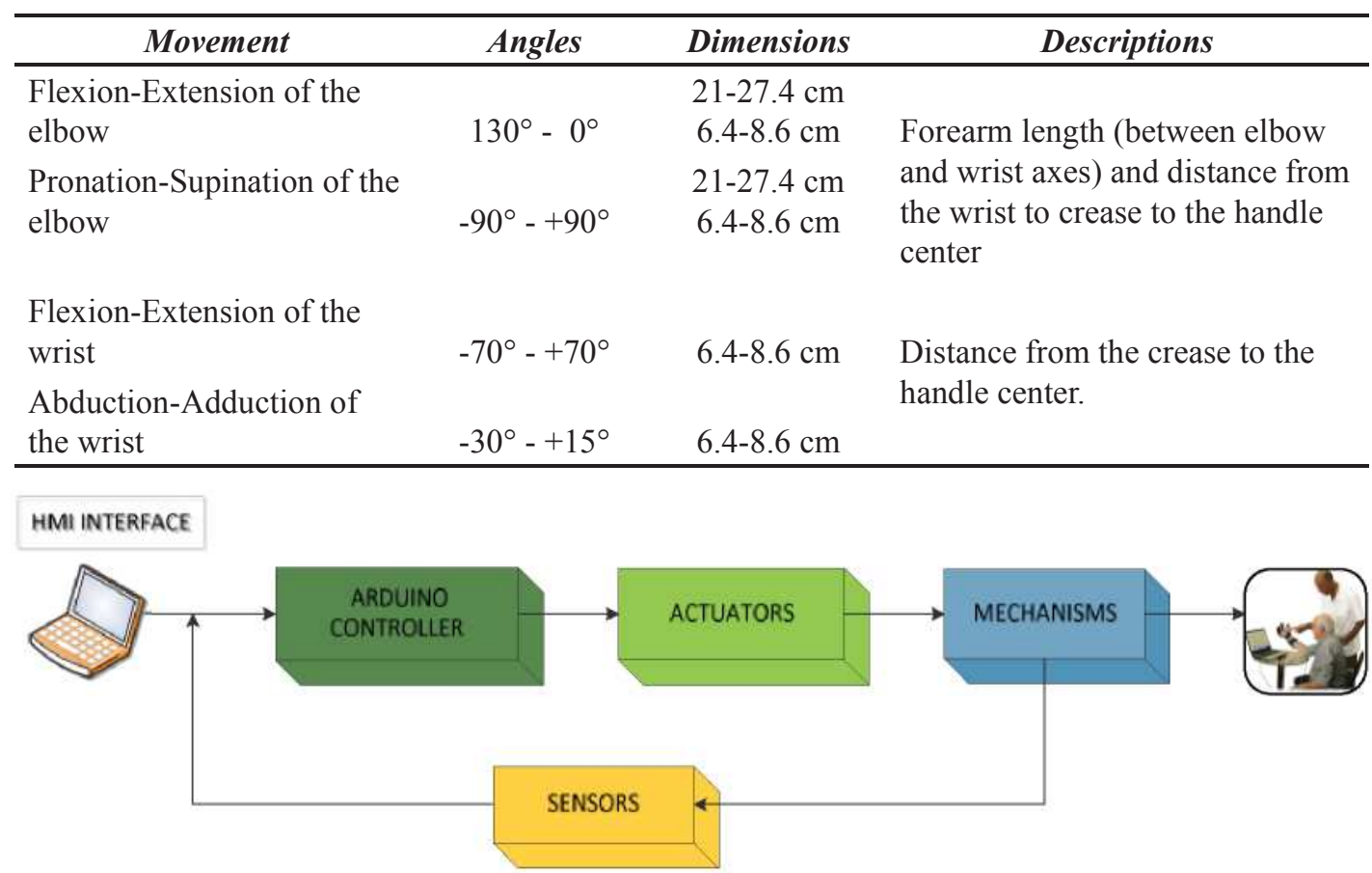

Figura 1. System's General Diagram.

A. Mechanical Design

To simplify the mechanical design, it was divided into four areas of design, as shown in Figure. 2.

The torque of every movement was calculated in order to select the actuator that will execute the movements. The result for flexion-extension of the elbow is $10.15 \mathrm{Nm}$, pronation-supination of the elbow is $4.19 \mathrm{Nm}$, flexion-extension of the wrist is $1.25 \mathrm{Nm}$ and for abduction-adduction is $1.37 \mathrm{Nm}$.

All of these results consider the masses of the hand $(0.73 \mathrm{Kg})$ and hand and forearm $(3.13 \mathrm{Kg})$. For this reason, the Torxis i00600 servo which has a torque of $11.3 \mathrm{Nm}$ is the more appropriate for this project.

The Table 2 shows the mechanical design of the prototype pieces and a brief description of each one. In the section called Coupling Mechanisms of Table II, it is shown the four different adaptations for each movement. It is possible to use the adaptations for both arms, left and right arm without any problem.

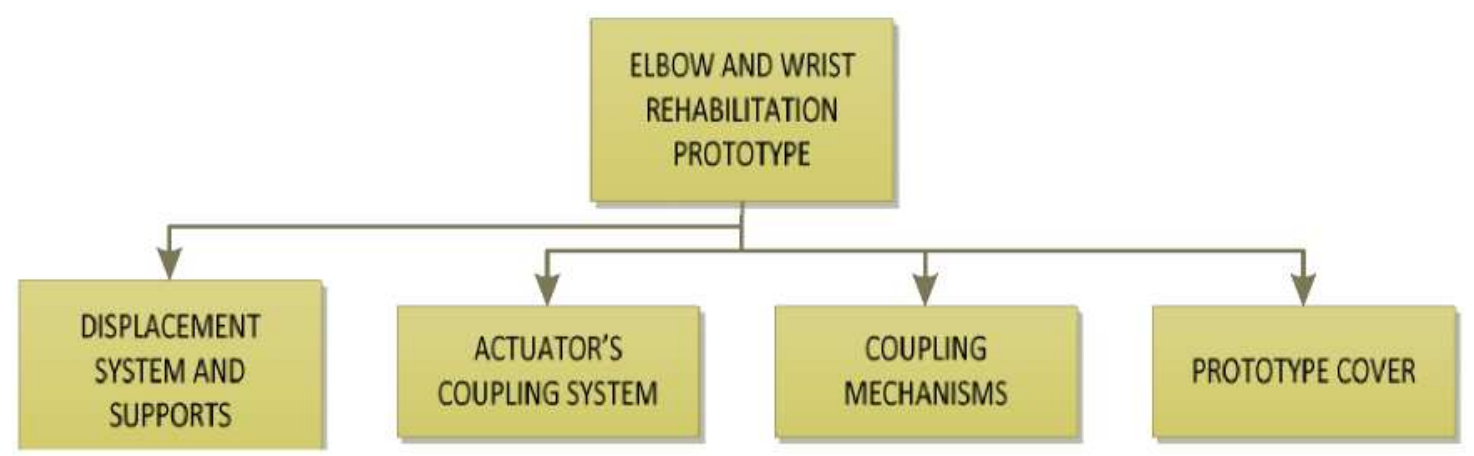

Figure. 2. Mechanical Design. 
TABLE 2. MECHANICAL DESIGN OF THE PROTOTYPE PIECES

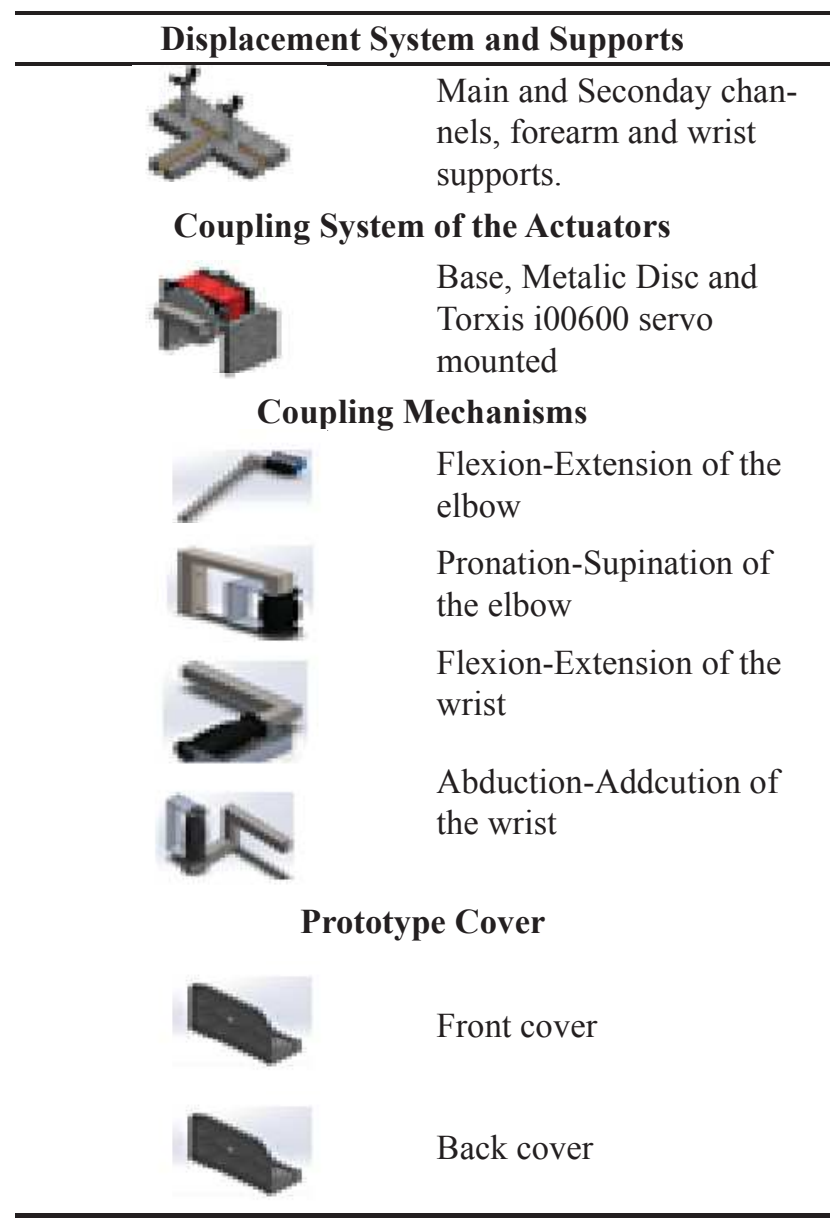

\section{B. Electronic Design}

The electronic design is composed of two main areas. A sensors' interface electronic board and a control board are in charge of all the actions executed by the actuator.

The circuits for the signal conditioning of the sensors of the angular position, sense of rotation and limit switches status are in the sensors' interface board. Meanwhile, the board control is an Arduino board which was selected by the number of Input/Output (I/O) pins needed for this project.

Because of the $14 \mathrm{I} / \mathrm{O}$ pins and the Pulse-Width Modulation (PWM) outputs necessary to control the Torxis servo, the Arduino UNO R3 board was selected to be used as the controller in this project.

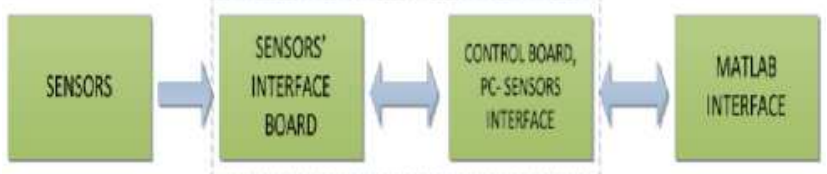

Figure. 3. Electronic Diagram.

\section{Programming}

The interface of the user programming allows the input rehabilitation data, movement selection, angular limits for each movement, motor calibration and status verification of the sensors. Consequently, the programming has been divided into two different processes which are the maintenance and the rehabilitation process, as shown in the Figure. 4.

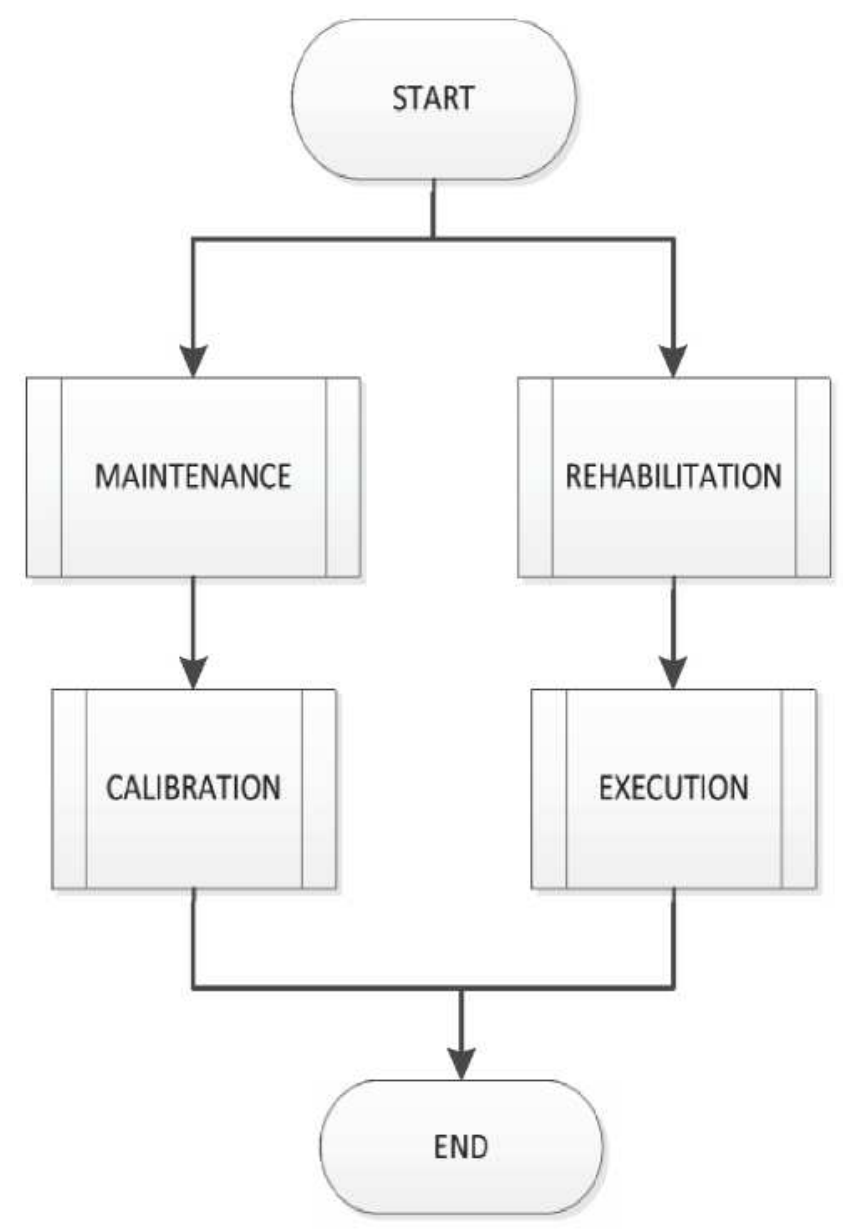

Figure 4. Programming flow diagram. 
The user chooses which process to execute between calibration of the servo and verification of the status of the sensors by selecting the corresponding option. See Figure. 5 that shows the maintenance interface.

To complete the rehabilitation process, the user should follow these steps:

1. Zone to rehabilitate (Elbow or Wrist).

2. Arm to rehabilitate (Left or Right).

3. Movement to execute (Flexion-Extension, Pronation-Supination, Flexion- Extension, AbductionAdduction).

4. Duty cycle input (Minimum and maximum angles, number of sets and repetitions, speed).

5. Serial port.

6. Duty cycle verification.

7. Process execution.

The Figure. 6 shows the user's interface executing a rehabilitation process.

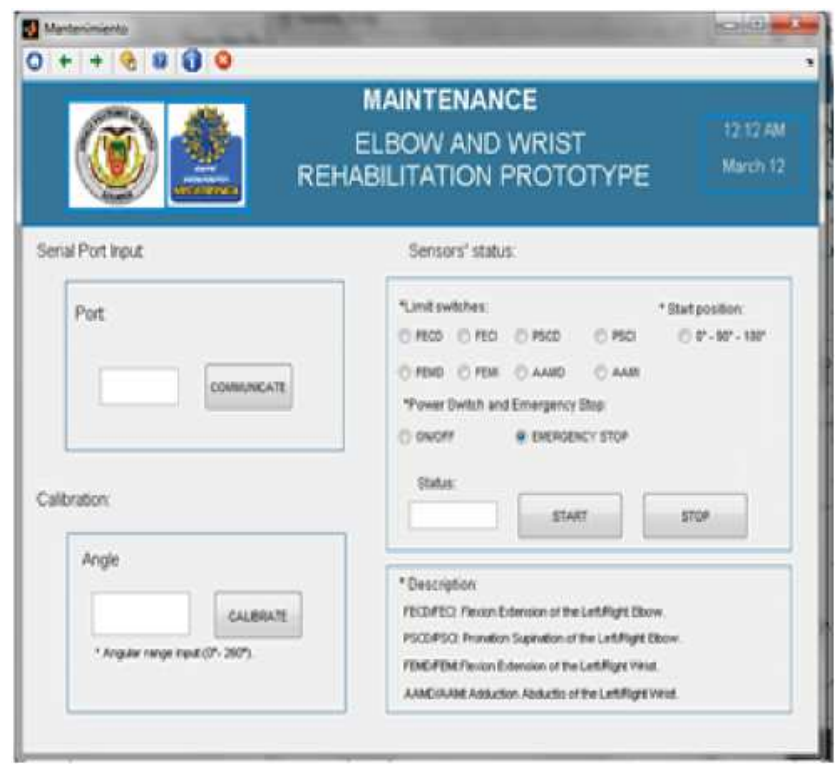

Figure. 5. Maintenance interface.

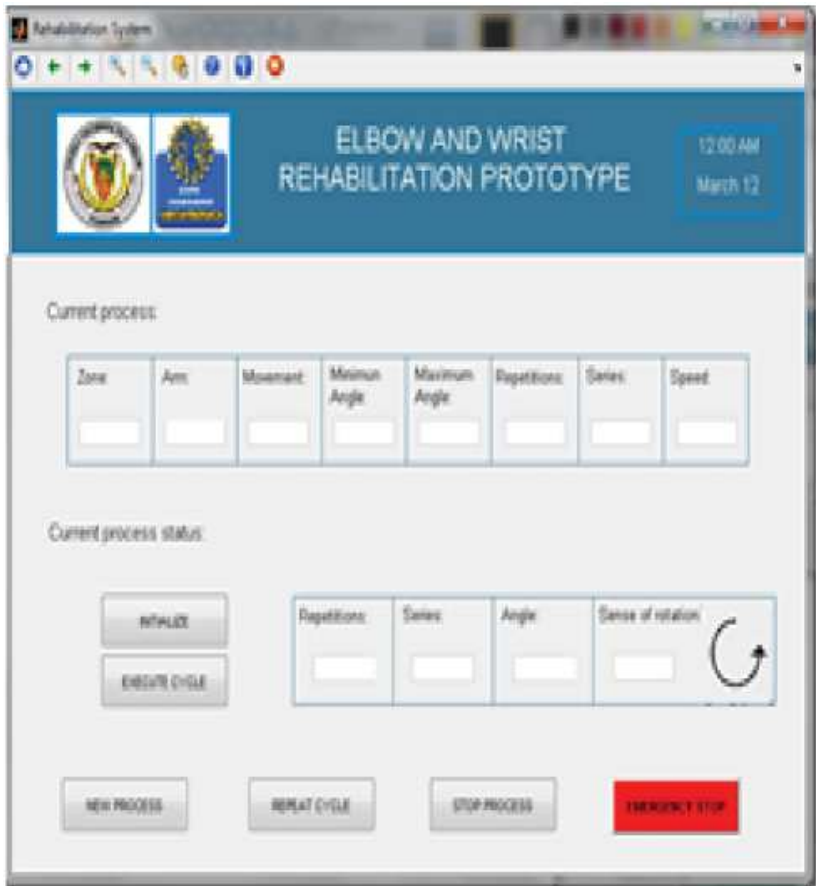

Figure 6. Rehabilitation process execution.

3. EVALUATION TO VALIDATE THE PROTOTYPE

Following a test protocol with different tests, the functioning of the prototype has obtained the results detailed in this section. The percentage of error was calculated using (1).

$$
\frac{- \text { experimental value }}{\text { true value }} * 100 \%=\text { error }
$$

TABLE 3. ANGULAR SHIFT IN SERVO TESTS

Angular Shift in Servo Tests

\begin{tabular}{ccc}
\hline Angular Shift & N. of Tests & Error (\%) \\
\hline $0^{\circ}$ & 11 & 0 \\
$1^{\circ}$ & 7 & 1.35 \\
$2^{\circ}$ & 8 & 1.65 \\
$3^{\circ}$ & 4 & 3.31 \\
\hline
\end{tabular}

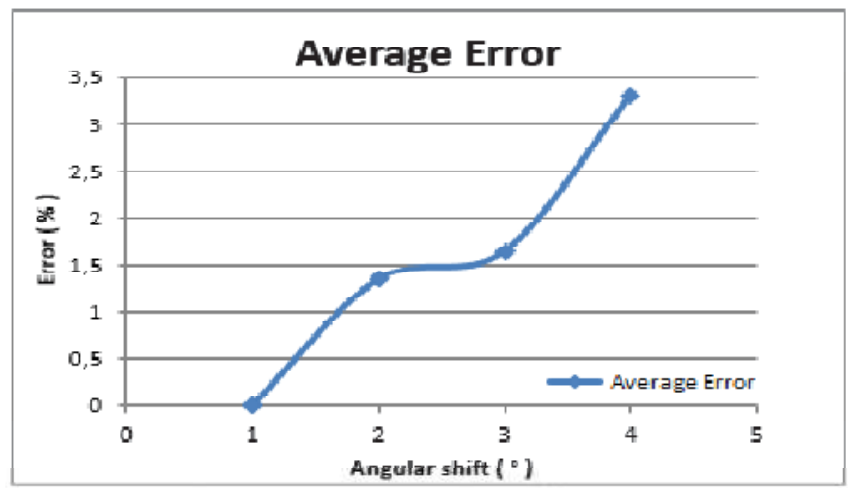

Figure 7. Tendency error vs angular shift. 
The greatest angular shift tested in 30 servo mobility essays is $3^{\circ}$ which represents an error of $3.3 \%$.

Testing was done on a person who had prior elbow and wrist fractures. This test was repeated for several days in order to obtain the development of the patient using the prototype. As shown in the Table IV and Figure. 9, the patient increased the mobility of elbow and wrist.

From the testing done we can observe that the patient improved the mobility of the joints within the therapy sessions. Besides, the physiotherapists in charge of the patient noticed that using this prototype was beneficent for the patient who was only using conventional methods previously.

TABLE 4. PATIENT TESTS DURING REHABILITATION WITH THE PROTOTYPE

\begin{tabular}{ccccc}
\hline Day & \multicolumn{2}{c}{ Wrist } & \multicolumn{2}{c}{ Elbow } \\
& Flexion & Extension & Pronation & Supination \\
\hline 1 & $-50^{\circ}$ & $45^{\circ}$ & $-70^{\circ}$ & $45^{\circ}$ \\
2 & $-65^{\circ}$ & $65^{\circ}$ & $-90^{\circ}$ & $55^{\circ}$ \\
3 & $-70^{\circ}$ & $70^{\circ}$ & $-90^{\circ}$ & $65^{\circ}$ \\
4 & $-70^{\circ}$ & $70^{\circ}$ & $-90^{\circ}$ & $68^{\circ}$ \\
5 & $-70^{\circ}$ & $70^{\circ}$ & $-90^{\circ}$ & $70^{\circ}$ \\
6 & $-70^{\circ}$ & $70^{\circ}$ & $-90^{\circ}$ & $73^{\circ}$ \\
\hline
\end{tabular}

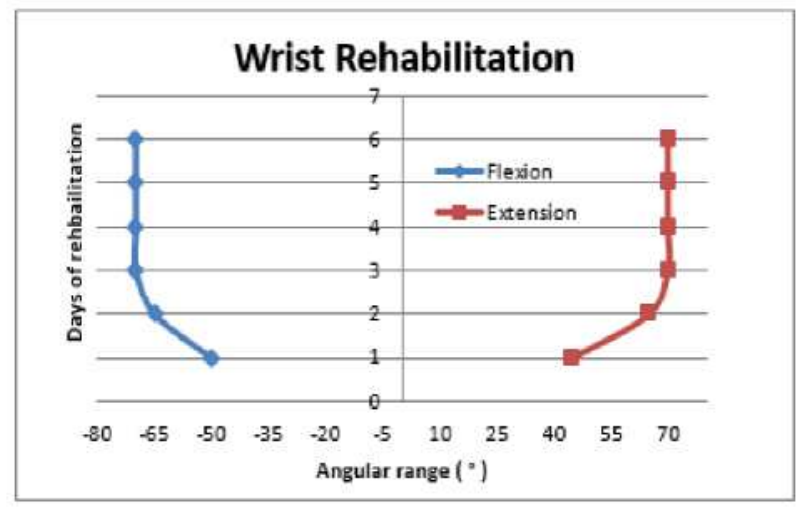

Figure 9.Patient's angular mobility per test.

\section{CONCLUSIONS}

The prototype achieved the proposed movements. In other words, it is able to execute flexion-extension, pronation-supination of the elbow and flexion-extension, adduction- abduction of the wrist regarding the angular anthropomorphic limits. These angular limits are considered for an adult patient to achieve full joint mobility in the first and second phases of rehabilitation.
The biomechanics of the upper extremity was the most important consideration when defining the angular limits of each movement because the whole design depends on these values to make this prototype comfortable and safe for the patient.

Electronic circuits were designed to avoid mistaken signals. For this reason, the sensors' interface board consists of conditioning circuits to determine the sense of rotation and to verify the limit switches' status. Subsequently, the signals obtained in this board are properly transmitted to the control board.

The application of Guide, graphical Matlab module, permitted the creation of a friendly and easy to understand graphical user's interface. In addition, through the programming made in this software it is possible to control the signals sent and received from the control board guaranteeing the correct input data, sense of rotation, angle, limit switches status and the current rehabilitation process visualization.

As this prototype has symmetry, it is possible to put the adaptations for the different movements for the right and left arm easily.

To verify the adaptability of the prototype, several tests were made on healthy males and females of various heights. According to the results of these tests, any adult person is able to use and feel comfortable because of the adjustability of the displacement system and the supports.

The fact that the percentage of error obtained was between $\pm 3^{\circ}$ in all of the tests, ensures safety to the patient, and demonstrates that this prototype is accurate and has a high repeatability which makes of it an attractive product for the therapy sessions of wrist and elbow rehabilitation.

From the testing done on a patient diagnosed with elbow and wrist fracture test, it may be concluded that the patient improved in the mobility of both joints using the rehabilitation prototype, within several days. Therefore, this project fulfilled the goal of progressively improving the mobility of the complete angular range of the corresponding movement. It is important to mention that due to the degree of pain and nature of lesion that the patient presented, she could only perform flexion-extension of the wrist and pronation-supination of the elbow. 


\section{BIBLIOGRAPHY}

1. William, D. A robot for Wrist Rehabilitation. Springfield;2001.

2. Wrui, P. Guía de diseño en movimientos repetitivos [sede Web]. Venezuela[access May 10, 2013]. Publicaciones. Obtained from: http://ergonomiavenezuela.org/guia-de-disenoen-movimientos-repetitivos/

3. Tilley, A. The Measure of Man and Woman: Human Factors in Design, The Whitney Library of Design. New York; 1993.

4. Norton, R. Diseño de Maquinas. Prentice Hall; 1999

5. Arduino UNO[sede Web].(2013). [access May 15, 2013]. Products: Boards.Obtained from: http://arduino.cc/en/Main/ArduinoBoardUno 